Andersen and Andersson emphasize thalamic at the expense of cortical function in electrocerebral activity and it would perhaps be unfair to expect otherwise. The monograph should provoke discussion and further enquiry. It can be warmly recommended to everyone interested in fundamental electroencephalography and brain function.

A. GIJass

\section{APPROACHES TO REGENERATION}

Cellular Biology of Vertebrate Regeneration and Repair By Anthony J. Schmidt. Pp. xi +420 . (University of Chicago Press: London, November 1968.) $157 s$.

As indicated by its title, this book does not deal with regeneration in invertebrates and in fact it is concerned chiefly with the limbs and tail of Amphibia. The healing of skin wounds in mammals is also considered, more briefly, for comparison. There is no specific account of organs such as the liver which probably regenerate extensively in all classes of vertebrates. Knowledge of regeneration in cyclostomes, fishes, reptiles and birds is limited, of course, but it would permit some useful comparison between classes.

The title also expresses an emphasis on regeneration processes at the cellular and sub-cellular levels of magnitude though, inevitably, tissues and their interactions often come into the picture. There is also a section on systemic and local factors which affect regeneration, so that the scope in these respects is broader than the title implies.

The book could scarcely be considered narrow in scope, in view of its ninety pages of 1,450 references. This compilation will be most valuable for all in the field. It includes many early works, gives full titles and has been prepared with great care: I found only one reference in the text which was absent from the bibliography. In contrast, there are a number of minor errors in authors' names, and the like, in the text, and the index looks thin.

Because the book also centres very manifestly on the author's own contributions to the subject, the inescapable implication is that these have been very substantial and broadly based - and all in the short space of one decade. Inevitably, the book has some of the shortcomings as well as the virtues of this situation. It has freshness and energy, but it has gaps (particularly in background), errors in perspective and signs of haste (in proof-correcting, for example). There is, perhaps, also a tendency to underacknowledge earlier books and reviews in the field. Korschelt (1927), for instance, is surely a classic, while Abeloos (1932) and Millot (1931) deserve a place in comprehensive, general bibliographies. Schmidt no doubt is justified in eschewing the "theoretical vaporizings" (to quote a compatriot zoologist) of earlier reviewers, though not in overlooking some of their useful contributions. Equally, of course, the author's own theoretical ventures must be appraised critically-not all will agree with the delimitation of "blastema", for instance.

The author's emphasis on limited aspects of recent research can scarcely give a well-proportioned picture for young zoologists who should constitute the book's main public. Nevertheless, as a record and interim report of the present stand of Schmidt with regard to research on regeneration, the book is as valuable as it is stimulating; it should certainly promote interest in, and direct research along, the author's main paths-the biochemical and the cytological. It is essential to know the metabolic and other chemical changes in regenerating systems at least as well as the morphogenetic changes are known, because they are likely to provide information which the latter alone never could. The author's whole-hearted application, in his work and reviews, to the initial problem of plotting the basic metabolic pattern deserves full credit.
It is an essential launching-pad for the really exciting phase, of research into the metabolites specific to the process, leading to the actual identification of such menin-the-moon as "evocators", "inducers", "organisers", and the like. Morphogeneticists may be pardoned for any present scepticism and restiveness about the chemical approach - this adds to the magnitude of the challenge. At the present stage, however, Schmidt is preoccupied with the basic metabolism, and he sometimes appears to forget that the centre of interest is the differences from, rather than the resemblances to, normal metabolism.

The organization of the book is open to some criticism. Sections other than chapter three (morphogenetic changes), part two (metabolites and metabolism) and chapter nine (endocrine factors) rouse some suspicion of paying mere lip-service to comprehensiveness. This impression is not improved by the final part which, despite its novel and intriguing heading, seems rather unmotivated and earthbound. Some of the headings do less than they might for the synopsis of the book.

The author has taken some liberties with English (and Latin) usage; for instance "overly", "interpretating", "intrafiberal", in loco meaning in situ, "temporally obligated" (correlated in time), none of which seems justified and could give much trouble to those less than fluent in the language. The same might be true of some of the technical terms: "muscle terminals" (? cut-ends), "third intention" ( ? tertiary intention), "pleuripotent" (pluripotent) and "analyn" (alanine).

There are a few factual errors such as using methyl green and pyronin for a fuchsin reaction, and some of the bioelectrical statements, but it is perhaps for the innocent to cast such stones.

The quality of both the contents and publication deserves due credit, but the price in sterling is high.

A. E. NeEDham

\section{RUSSIAN PHYSIOLOGY}

\section{Physiology and Pathology of Membrane Digestion}

By Aleksander M. Ugolev. Translated from the Russian by Jacob A. Stekol. Pp. xvi + 226. (Plenum Press: New York, 1968.) \$15.

THIs is a disappointing book. It would have been justifiable to hope that Ugolev would have produced an illuminating account of problems with which he has been prominently concerned. This would give us an insight into an interesting aspect of Russian physiology which is otherwise available only to those of us who are fluent in Russian. Unfortunately, he has attempted to cover too wide a field, so that there is alternation between very detailed accounts of the experimental basis of some of the conclusions and wholly superficial accounts of the basis of other conclusions.

The main thesis of the book is that there is a process of intestinal digestion which takes place on the surface of the cells of the intestinal mucous membrane and that this is at least as important as digestion in the lumen of the intestine brought about by the enzymes of the secretions of the pancreas and the intestine. This thesis has been generally accepted and there is much work published in English to support it. Ugolev himself published a review in English in 1965 (Physiological Reviews, 45, 555), and what would have been helpful here would have been a fuller account in English of the experimental work rather than of the basic ideas.

There is, indeed, more experimental detail in this book than in the review, but it does not strengthen the argument, because it is rarely full enough. Much of it is in the form of diagrammatic presentations of the results of experiments whose design has not been described, and in a number of instances there is no reference to the paper in 